\title{
Peertechz
}

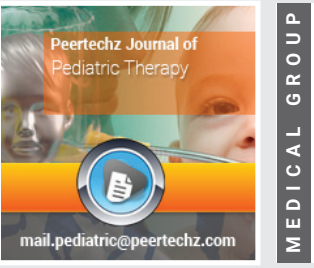

\section{Neonatal and infantile abuse}

\section{in a family settings}

\section{Giulio Perrotta*}

Psychologist sp.ed Strategic Psychotherapist, Forensic Criminologist, Jurist sp.ing SSPL, Lecturer,

Received: 06 June, 2020

Accepted: 03 October, 2020

Published: 06 October, 2020

*Corresponding author: Dr. Giulio Perrotta, Psychologist sp.ed Strategic Psychotherapist, Forensic Criminologist, Jurist sp.ing SSPL, Lecturer, Essayist, Italy, E-mail: giuliosr1984@hotmail.it

https://www.peertechz.com

\section{Check for updates}

\section{Abstract}

This work focuses on the issue of mistreatment in neonatal age in family contexts and in particular on socio-environmental and psychopathological elements. The first part focused on the general profiles, highlighting, in particular, the defining contexts and the different types of implementation of the mistreatment, to focus more carefully on the social, environmental, and psychopathological elements, to complete the analysis structurally. However, it is evident that the mistreatment perpetrated in damage to a living being in neonatal age represents, beyond the seriousness of the damage reported, it represents a clear sign of a severely disturbed personality, which needs containment and neutralization, to avoid damage and dangers to itself and other.

\section{Contents of the manuscript}

\section{General profiles}

Neonatal mistreatment consists of one or more inadequate behaviors, possibly repeated over time, with or without a precise criminal design, towards an infant under the age of two months and involves a substantial risk of causing physical injury and/or emotional. What the victim of abuse is older will talk about child maltreatment, although the substance of deviant or clinically relevant behaviors remains practically unchanged [1].

In general, four types of "abuse" are recognized [2].

"physical abuse", consisting of inflicting physical damage or engaging in actions that create a high risk of body trauma. Specific forms include shaking, falls, blows, stings, and burns. Especially in the first months of life, during clinical monitoring, the most frequent relevant data are head injuries, bone fractures, and burns (some even serious). In detail, however, frequent skin lesions such as handprints or oval fingermark caused by slaps, grips and shaking, long band bruises (caused by whipping with a belt), subtly arched bruises (caused by whipping with elastic), burns caused by cigarettes or hot bodies, symmetrical burns of the upper or lower limbs, bite marks, thickened skin or scars at the corners of the mouth caused by gagging, patchy alopecia, with variable hair length, caused by hair-tearing, up to bruises and more or less marked petechial signs, single or multiple fractures, simple or displaced, of the cranial bones, ribs, vertebrae, limbs, and long bones, ending with internal traumas and focal neurological alterations as a consequence of the reported traumas.

"sexual abuse", consisting of physical abuse characterized by a sexual impulse. Forms of sexual abuse include intercourse, i.e. oral, anal or vaginal penetration, but also simple harassment, i.e. genital contact in the absence of complete intercourse and forms that do not involve physical contact with the perpetrator of abuse, such as exposure of the genitals by the abuser, to show sexual material to a child, and to force a child to participate in a sexual act with another child or to participate in the recording of pornographic material. The hypotheses of sexual violence, however, do not include the "exploratory sexual game between children", which is characterized by the following elements: a) the children must not have a difference in their age greater than three years; b) children must both be under the pre-pubertal age; c) the children must not have previously manifested sexual drives or desires contextualized in contacts of a sexual nature or any case inappropriate concerning the reference context; d) the physical contact of the genital areas or the simple earning must take place without violence or external coercion and must not manifest itself in a framework of pleasure with an erotic and / or sexual background. Otherwise, any action against a child that is carried out for the sexual gratification of an adult or a significantly older child constitutes sexual 
abuse and falls within the symptomatic framework of the "pedophilic paraphilic disorder". The risk of sexual abuse is increased in children cared for by multiple people or by a parent who has several sexual partners "emotional abuse", consisting of inflicting emotional trauma through the use of words or actions (not necessarily capable of causing physical damage). Specific forms include scolding a child by screaming or shouting, despising him by diminishing his abilities and accomplishments, intimidating and terrorizing him with threats, and exploitation or corruption by encouraging him to deviant or criminal behavior. Emotional abuse also occurs when words or attentions are omitted or denied, substantially becoming emotional negligence (for example, ignoring or rejecting a child or isolating it from possible interactions with other children or adults). In neonatal age and early childhood, emotional abuse can attenuate emotional expressiveness and reduce interest in the environment, making the infant seemingly unaffected and insensitive to stimuli. Emotional abuse, if perpetrated over the months, especially in early and second childhood, often leads to a developmental deficit that can be incorrectly diagnosed as intellectual disability or organic disease. A delay in the development of social and linguistic skills often results from inadequate stimulation and parental interactions. The child victim of emotional abuse can be insecure, anxious, distrustful, superficial in interpersonal relationships, passive, and excessively worried about pleasing adults. Children who are rejected can have very low self-esteem, maintaining this pattern even in adulthood, reinforcing it in the negative. Children who are terrified or threatened may appear afraid and avoidant. The emotional consequence on the child generally becomes evident in school age, when he develops difficulties in establishing relationships with the teacher and with the group of peers. Frequently, the emotional consequences are appreciated only after the child is placed in another environment, or after aberrant behaviors fade and are replaced by more acceptable behaviors. The emotional picture also includes a particular form of delegated hyper attention, called "Munchausen syndrome by proxy": parents (mostly mothers), who usually enjoy a very positive reputation among medical personnel, invent symptoms that their child, at what they say, should have (fever, cramps, bleeding, etc.) or provoke them with the most varied manipulations. Both things cause numerous analyzes and unnecessary medical interventions. The mother is thus placed at the center of attention as a reference person worried about her son who suffers from an unknown disease and who consequently cannot be helped. In this way, he obtains a gain of attention secondary to the "illness" of his son.

"Neglect", consisting in the inability to respond or meet the basic needs of the child, physical, emotional, educational and medical, both in the hypothesis of neglect (poor care) and in hyper-cure (other than episodes of manic or fictitious disorder) and neglect (distorted or unsuitable treatment). Neglect, referring precisely to the phenomenon of neglect, differs from abuse because it generally occurs without malicious intent and therefore without the conscience and the will to cause harm or endanger the person. In this sense, negligence can consist both in the implementation of a physical modality (the inability to provide adequate levels of nutrition, clothing, shelter, supervision, and protection from potential damage), and affective (the inability to provide affection or love or other types of emotional support), educational (the inability to enroll a child in school, ensure school attendance, or provide education at home) and/or health care (the inability to ensure appropriate care or treatment for the child necessary for trauma or physical or mental disorders or even the failure to provide preventive care which, by aggravating themselves, expose the infant to health risks). Carelessness usually results from a combination of factors, such as poor parenting and stress-adaptive ability, non-supportive family systems, and stressful life circumstances. Neglect often occurs in impoverished families during financial or environmental stress situations, particularly in those where parents also have mental illnesses (typically depression, bipolar disorder, or schizophrenia), use drugs or alcohol, or have limited intellectual capacity. Children of single-parent families may be at risk of carelessness due to lower-income and fewer resources available. Malnutrition, fatigue, poor hygiene, lack of adequate clothing, and delayed growth are frequent signs of inadequate intake of food, clothing, or protection. Slowing of growth and even death can result from fasting or exposure to extreme temperatures or climate. Carelessness that leads to inadequate surveillance can result in preventable disease or injury. Often, however, these forms coexist, without ever falling into the malicious hypothesis of abuse.

It must be said, however, that often these forms of mistreatment coexist and the overlap in clinical and judicial practice is very frequent.

According to the most accredited statistics, the most common risk factors are therefore the presence of clinically relevant psychopathologies of the parents of minors, social isolation and marginalization, work, housing, and economic difficulties, too early a motherhood or rapid succession of various pregnancies, the state of unwanted or otherwise unforeseen gestation, social and/or emotional insecurity, previous personal experiences of abuse or neglect, delinquency or conduct deviant socially, domestic violence, physical pathologies of the infant and too demanding expectations from parents $[3,4]$.

\section{Socio-environmental and family variables}

In the first years of life, the infant is completely immersed in the family and environmental context, and therefore the risk of being abused or neglected is statistically more likely in those dysfunctional families or degraded and socially deviant environments. The factual circumstances described in the anamnesis, based on the narratives of the infant's family members, must always be compared with the socioenvironmental and family factors of reference, to discriminate between socially accepted behaviors (albeit to the limit) and dysfunctional behaviors in able to cause danger (neglect) or damage (abuse) to the infant. Undoubtedly, severe corporal punishment constitutes "physical abuse", but for lesser degrees of physical and emotional punishment, the socially accepted boundary varies from one culture to another [5]. 
It is much easier to define neglect or abuse in an infant who already has a socially acceptable age to interact with other peers (for example school age): in these hypotheses, the comparison is simpler, since he is living in an "extended" social context concerning the family only, certain behaviors are immediately detectable and therefore analyzed; in the newborn, also missing the verbal and narrative component, any deviant or clinically relevant behaviors can be analyzed only if there are witnesses able to narrate the episodes that have occurred or traumatic clinical findings on the infant's body in total or partial discrepancy with the narrations of the parents or caregiver. The assessment becomes complicated when the socio-environmental context of the families of reference is degraded or deviant: in such circumstances, it often happens that behaviors normally considered by national law as dysfunctional or abusive concerning corrective means, such as slapping (which integrates the crime of beatings) or physical aggression (which integrates the crime of injury, according to gravity), are instead considered socially accepted or even educational [6].

In the same way, some religious and cultural practices, such as female genital mutilation, socially accepted in some African cultural contexts, are so extreme as to constitute an abuse in hundreds of other western and eastern contexts. As is the case with some folk remedies, such as coining, cupping, and irritating compresses, which can often create lesions of the epidermal layer, but which hardly cross the border between acceptable cultural practices, neglect, and abuse [7].

Even strictly religious beliefs, such as the ban on transfusions between patients not belonging to Jehovah's faith, can be real abuse, but only in the hypothesis that the proposed clinical treatments are life-saving, resulting in the death of a child [8].

Instead, the personal belief, collectively accepted, of certain health practices, useful and necessary, but experienced as harmful and dangerous, as happens with mandatory vaccinations, is completely different: in such cases, based on the cultural and social context of reference, there is discussion case by case, on the need or not to provide for civil, criminal and administrative sanctions for offenders, in addition to the danger of possibly losing parental authority over minor children, for confirmed neglect of health obligations [9].

\section{Deviant and psychopathological behavior}

Each of the four hypotheses of abuse indicated above (physical, sexual, emotional and neglect) has a negative psychological impact on the victim of abuse, both on the stage of normal psycho-emotional development and on the consolidation of behaviors that will then better define the character and therefore the personality, causing specific relevant clinical conditions capable of impacting the infant's mature mental health. Children who are frequently victims of abuse are often afraid, irritable, and sleep in a fragmented and disturbed way. They may have symptoms of depression, post-traumatic stress reactions, or anxiety. Sometimes victims of abuse show symptoms similar to those of Attention Deficit Hyperactivity Syndrome and are mistakenly diagnosed with it. Violent or suicidal behavior can occur, especially in pre-adolescent victims. Generally, mistreatment can be attributed to the loss of impulse control in the parents or the infant's caregiver. And this can happen for several factors [10]:

a) Character and personality components: Parents' childhood itself may have been lacking in affection and warmth, may not have led to the development of adequate self-esteem or emotional maturity, and in many cases involve forms of victimization in episodes of abuse. Parents who perpetrate abuse or episodes of serious neglect could pour the frustrations and fears resulting from the hardships they suffered into children or consider their child as a source of unlimited and unconditional affection, seeking in him the support they have never received, creating made a relationship based on unrealistic expectations that children have to make up for. The disappointment of expectations, feelings of inadequacy, poor control of impulses, and more or less diagnosed psychopathologies (such as depression, bipolar disorder, and personality disorders) can explain these behaviors etiologically.

b) Use of narcotics and/or alcoholic substances: They can trigger impulsive and uncontrolled behavior towards their children, further decompensating their fragile position, increasing the risk of episodes of abuse.

c) Strong intolerance to frustration: The conduct of the child, especially in the first months of life, up to three or four years of age, can be particularly irritable, demanding or hyperactive and can provoke the anger of the parents, especially in those subjects who have a low tolerance to frustration or who are emotionally unstable.

d) Total or partial lack of a stable and lasting emotional bond, with a lack of commonality of common family goals and objectives: At times, strong emotional ties do not develop between parents and between parents and children and this lack of bonding commonly occurs in the case of premature or sick infants, separated early from their parents, or with children who are not biologically their own, further increasing the risk of abusive episodes.

e) Situational and socio-environmental stress: Any family tensions, health problems, financial difficulties, lack of emotional support from close family members or friends, and interpersonal misunderstandings can exacerbate episodes of abuse.

The analysis of the behavior of all the actors involved in the narrated episodes is therefore extremely important, in particular of the parents, family members or more generally of the caregiver, to more easily distinguish the hypotheses of socially accepted and/or tolerated behavior or episodes which deserve special attention, because they are dysfunctional (and therefore deviant) or even manifestly pathological. If a person 
engages in behavior that moves away from the dominant social models and the current legislation, it is said that he is "deviant". All social groups create norms and try to enforce them, as the norms indicate the right and wrong types of behavior, also based on the moral of the group of origin. Generally, people who live within a given society tend to internalize their common rules and reference social models; therefore social influence leads to conformism, that is, to the tendency to approve the rules and opinions of "experts" with respect for the community. In the common representation, deviance and crime are concepts that refer to the idea of social maladjustment; in reality, crime can also have a more detached connotation from the degraded contexts of the city suburbs (for example, economic crimes). The notion deviance recalls the sociological notion of "anomia", introduced by the French Durkheim, towards the end of the 19th century, and means "absence of norms", that is, a state of conflict between the expectations of the regulations and the reality experienced by the subject, a discrepancy between the objectives that the subject wants to achieve and the reality that society offers to achieve them. So anomaly exists when people engage in behavior without rules and morality, hostile to social norms, we can, therefore, understand anomaly as the antithesis of solidarity, the most extreme consequence of which is for example suicide, in to which a detachment and a total rejection from the community is chosen; on the other hand, deviance does not completely go beyond the rules and social hostility is never absolute $[11,12]$.

From a more strictly psychological point of view, however, there are several explanatory models of "deviant behavior" [1315]; among the main ones:

a) Biological-constitutional model: A biological determinant at the basis of the deviant behavior is assumed, a more or less marked trend of genetic origin, and any correlations are sought between the genetic or somatic characteristics of the individual and his behaviors.

b) Psychoanalytic model: In this context, the propensity to deviant behavior can be traced back to a process of non-ideal psychological growth: the formation of the superego, that is, the construction of behaviors, values, taboos, and teachings learned from the relationship with parents, is occurred incompletely with consequent lack of control of the drives, or by identification with criminal figures. More recent psychoanalytic theories trace the criminal conduct back to emotional disturbances matured in the very first years of life, in the relationship with the mother figure, or to socioeconomic and affective contexts of serious deprivation.

c) Behaviorist model: According to this model, social norms are learned through associations between a certain behavior and its consequences. So if a child commits a wrong act, he will receive penalties from his parents and this will allow correct learning of the rules. However, some people are unable to treasure certain conditions, due to personal characteristics that lead them to assume deviant behaviors more easily, for example, extroverts. The English psychologist Eysenck, who lived in our century, was also interested in the study of personalities and analyzing that of the "extroverts", asserted that these are rather insensitive to conditioning.

d) Psycho-social model: In this context, all environmental components are dealt with, such as family, cultural and economic conditions that can favor deviant behavior. Those who come from disadvantaged families can try to be welcomed into groups where the negative identity finds support and support and where the worries of their superego are silenced by a group superego that replaces it.

In recent times, however, there has been a tendency to consider crime and deviance as the result of a complex interaction of several factors, which are difficult to isolate from each other, which intervene to define the type called "psychopathy", undoubtedly the most dangerous psychopathology about management and to the care of an infant and a person in general. Psychopathy is considered an extreme form of "Personality Disorder", in the narcissistic and antisocial variants, which includes both adaptive and maladaptive behavioral traits, depending on the severity and intensity of manifestation of the symptoms. The typical manifestations of psychopathy concern relational, emotional, and behavioral dysfunctions with a prevalence of coldness traits, absence of empathy, guilt, and remorse, poor emotional representation of fear, tendency to exploit others, indifference towards social rules and poor development of a moral conscience. This personality disorder includes traits such as grandeur (typical of narcissistic disorder), the ability to experience only superficial emotions, lack of empathy, and disrespect for social rules (as occurs in antisocial personality disorder). The current conceptualization of psychopathy has been influenced by Cleckley's studies, who listed 16 diagnostic criteria that could be used to identify people with the disorder. Particular emphasis was placed on the psychopath's poor affective and interpersonal skills (superficiality, inability to love, lack of remorse, pathological lying) and on his antisocial behavior (poor impulse control, absence of planning, inability to learn from past experiences, delinquency, parasitic lifestyle). This notion of psychopathy was then operationalized in the following years with the development of the Psychopathy Checklist, which includes 20 items designed to measure these two dimensions of the disorder. Paulus and Williams have identified a psychological construct, used in forensic, clinical and managerial psychological research that they called "dark triad", which describes a "malignant" personality structure, characterized by the presence of three main traits: narcissism, Machiavellismand psychopathy, whichoccurinvaryingways and intensities and not always markedly pathological. Psychopathy is therefore characterized by a combination of personality traits that can be present in an individual at varying levels of severity and intensity, without necessarily reaching levels that make the clinical diagnosis of psychopathy possible. Just as the reduced ability to feel fear and emotional and emotional deficits represent a nuclear aspect of psychopathy, the presence of an alteration of the attachment system is responsible for the inability to build bonds typical of psychopathy. Karpman 
suggested that not all individuals with psychopathy were equal and exhibited the same type of traits. The author had identified two clinical subtypes of psychopathy: primary psychopathy (a term with which he indicated a hereditary condition of affective deficit characterized by the presence of superficial emotions, lack of remorse and empathy, interpersonal detachment) and secondary psychopathy (indicating term psychopathic traits acquired following experiences lived in a negative environment, such as impulsiveness, instability and emotional dysregulation, a self-injurious lifestyle). In general, therefore, the primary variant of psychopathy is associated with a reduced physiological, emotional, and neural reactivity which translates into a cold and superficial emotionality, but also in greater emotional stability compared to the second variant, which instead appears more dysregulated and prone to behavior self-harm. In the secondary variant, an aspect of greater physiological, emotional, and neural reactivity seems predominant. Attachment theory states that when parents or parental figures are unavailable and do not respond to the needs of the child, a form of emotional dysregulation and an individual's inability to regulate their emotions is likely to develop, resorting to alternative emotional regulation strategies. The trait of emotional dysregulation present in the second variant of psychopathy, results from the interaction of genetic factors and conditions of mistreatment and is associated with the presence of post-traumatic stress, other biological factors indicative of a high level of stress and secondary traits such as high level of distrust towards others, suspiciousness, narcissism and low level of pleasantness. Currently, studies conducted on psychopathy and romantic relationships indicate that psychopathy is associated with attachment disorders and the tendency to betray, to prefer short and disengaged relationships, tending to be based on the exploitation of the other. Considering that in psychopathy there is a disturbance of emotions and emotions, this dysfunctional aspect could be associated with the presence of a problematic (insecure) attachment; however, the research conducted on attachment and psychopathy is only partially reliable, due to the lack of consistency in the clinical and non-clinical samples observed, and the conceptualization difficulties related to attachment and psychopathy constructs. Even more serious is the extreme hypothesis of a "psychopathic pact or collusion" (in its sadistic, masochistic or mixed variants) between the partners, parents of the infant and both affected by personality disorders with little insight, where the child becomes the victim designated to suffer all kinds of harassment, denigration and abuse, with conscience and will, systematic and repeated over time, according to the scheme they devised. In this circumstance, the time factor is essential to prevent one or more episodes from culminating in the death event. As we know, the family is the basic nucleus in which we all normally grow up and which leaves us with a very profound imprint, regardless of subjective awareness. By forming a new family we tend to repeat the internal operating models that we learned as children, whether they are right or wrong. A "functional family" will promote the correct development of its members, allowing everyone to show their individuality; a "dysfunctional family" instead will create a toxic environment that will intellectually or emotionally invalidate its members and become fertile ground for a variety of psychological disorders. It is precisely on the concept of a dysfunctional family that we must stop when we think about families where there is child abuse [16-35].

\section{Clinical treatments and parental capacity assessments}

The physical examination is therefore the first fundamental step to confirm or not the presence of one or more episodes of abuse or neglect. The documentation of the medical history and physical examination must be complete and accurate as far as possible, including the recording of exact quotes from the history and photographs of the injuries. It is often not clear after the initial assessment of whether the abuse has occurred. In such cases, the mandatory reporting requirement of suspected abuse allows authorities and social workers to investigate; if their assessment confirms the abuse, appropriate legal and social interventions can be carried out. Both the medical history and physical examination provide indications of mistreatment. The suggestive characteristics of abuse in the anamnesis are different; the most important concern: the reluctance of the parents or the inability to provide a plausible reason for the injuries sustained; a history incompatible with the lesion or an apparent stage of resolution (old lesions described as recent); a history that varies depending on the source of information or the time spent; an anamnesis regarding injuries incompatible with the developmental phase of the child, in the absence of pathologies that can explain the findings (example, diagnosis of bone cancer or osteogenesis imperfect in the presence of multiple fractures with calcification differentiated over time); an inappropriate reaction from the parents regarding the severity of the injuries, or excessively worried or indifferent; delay in seeking appropriate treatment for injuries; narrative discrepancies and / or more or less obvious contradictions. However, suspicious clinical findings, such as injuries or bruises or fractures, cannot always be traced back to forms of abuse or mistreatment; to attribute them to such hypotheses the following elements must be taken into consideration [36]:

a) Age and psychomotor stage of the child: Some force is required to cause a hematoma: A child must fall or bump violently for a hematoma to appear without external intervention. This is only possible if the child has reached the corresponding psychomotor stage of development: infants cannot cause hematomas without external intervention, and even children with limited mobility forced into bed.

b) Localization: Hematomas for which abuse is not suspected are found in places where children typically get hurt: forehead, cheekbones, nose, chin, elbows, pelvis crest, knees, shins (Image 1 and 2). Suspicious hematomas are those above the "hat profile line", on the neck, neck, chest, back, belly, buttocks, and in the internal parts of the limbs. (Pictures 1-4).

c) Age: All hematomas that come from a single accident usually have the same color. Hematomas of a different color from each other must, therefore, be caused 

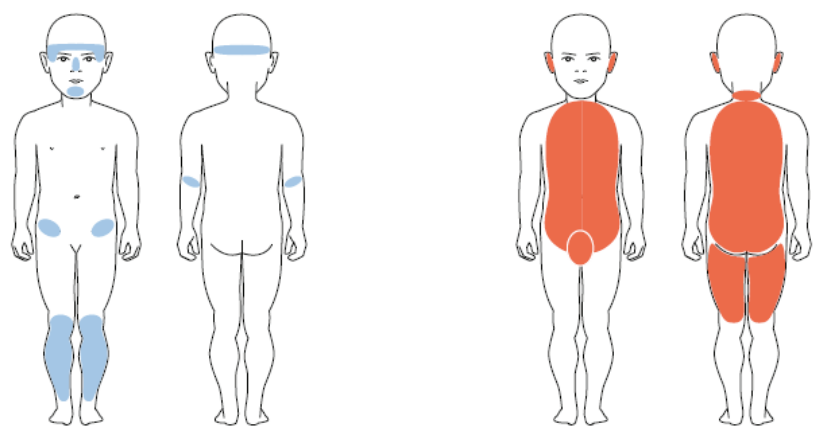

Picture 1-4: Localization of traumatized areas.

by traumas that occurred at different times and although the importance of determining the age of the hematomas according to their color has recently lost a lot of importance, the only rule left is that a yellowish coloration means that the hematoma is more than three days old.

d) Footprints: Footprints that can be combined with objects or parts of the body are practically proof of mistreatment. Examples: belt buckle, stick (double linear outline), cord or rope (loop), coat hanger, hand/ finger or bite.

e) Coagulation disorders: In the absence of clinical pathologies excluding abuse or mistreatment, such as vasculitis, Lichen, or Ehlers-Danlos Syndrome.

f) Thermal injuries: Most burns caused by an accident occur when the child takes hot drinks or dishes from the table or kitchen counter. This is only possible if the child has reached a certain stage of psychomotor development. From a similar accident a typical localization of the results of the burn: the chest, belly, possibly shoulders and chin are affected. The depth of the sunburn decreases in the craniocaudal direction. Another frequent scalding situation occurs when a parent or another person holds the child with one arm or knees and a boiling drink in the other hand. Sunburns due to mistreatment usually have sharp contours and are located mainly on the hands, feet, and in the anogenital area. They are parts of the body where a child cannot get a sunburn without the intervention of third parties, except possibly for the hands and feet, but in this case, they would have a different configuration. Furthermore, children touch hot objects or fire only because they do not recognize the danger (hot plate, red-hot oven door, etc.) or because they fall or trip over. Accidental contact with hot objects usually results in injuries to the palms of the hands or feet; in falls, burns are often combined with other injuries. Footprints of hot objects (grids, irons, and cigarettes) always give rise to suspicion of mistreatment, except for clinical syndromes able to explain the findings, such as dermatitis, Staphylococcal combustible syndrome, Epidermolysis bullosa and popular therapeutic practices of the Far East (cupping). g) Fractures: The detection of fractures in the infant skeleton is a fundamental point in the diagnosis of child maltreatment, especially when the fractures occur at a very early age or do not coincide with the description of the accident or with clinical pathologies such as osteogenesis imperfecta, osteopenia in following extreme prematurity or rickets.

h) Internal injuries: Internal injuries usually lead to a serious clinical picture that requires immediate hospitalization. Therefore only a few minor injuries and the syndrome of the shaken child will be treated here, for which in practice the emphasis is on prevention (how to behave with children who cry a lot). Shaking a child who is not yet able to stabilize the head in sagittal direction leads to serious intracranial and intracerebral lesions, without the need for the skull to undergo external impacts (and therefore without bruises or fractures). The main typical lesions are subdural hematomas, the so-called "shearing injuries" in the brain parenchyma (both also lead to a harmful increase in intracranial pressure) and hemorrhages of the retina and / or the vitreous body. Infants are affected, males more than females, with an apex of around five months. The trigger is almost always the (intense) crying of the infant (for this reason, male infants are most affected). The clinical picture presents itself with the symptomatic triad of altered state of consciousness (from irritability to coma), respiratory disorders (from bradypnea to apnea), and convulsions picture 5 .
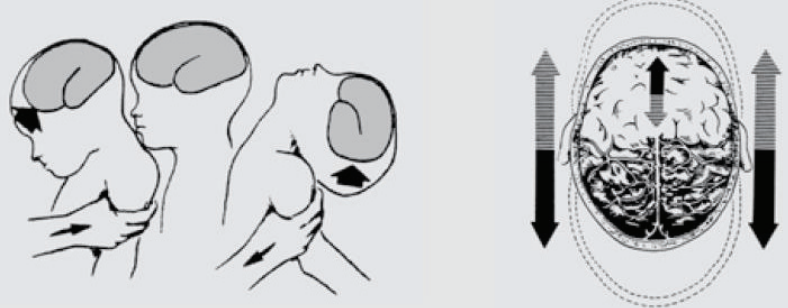

Picture 5: Infant shaking syndrome.

i) Poisoning: Altered states of consciousness or neurological findings should suggest the administration of psychotropic substances or medications to the child. Their presence is found in the urine and / or in the blood: immediately take the sample of both urine and blood if you have a suspect. By freezing the material, it can also be analyzed later or eliminated.

j) Findings from genital mutilation or sexual abuse: In confirmed clinical diagnosis of trauma related to abuse or mistreatment, the first treatment certainly concerns the need for medical care, simultaneously activating the procedure provided for in these cases in which mistreatment to the detriment of the infant is suspected. In both cases of maltreatment and cases of neglect, the approach with the family must 
still be caregiving, leaving the punitive profile to the competent authorities. In the event of neglect, a rehabilitation path of parental authority, if any, must be provided if the elements are clear and precise and in agreement to consider reintegration into the family context of origin possible; in the hypothesis of abuse, it is unlikely that there will be a full recovery of parental authority, by any personological data of the parents or caregiver, in addition to the profiles related to the judicial sphere. Anyone who reports abuse based on reasonable evidence and in good faith is exempt from criminal and civil liability; the public official, on the other hand, should report, under penalty of serious penalties being applied. The reports are then sent to the Child Care Services or other appropriate child protection centers. In most situations, it is appropriate for healthcare professionals to warn carers that a lawful report has been made and that they will be contacted, interrogated, and likely to be visited at home. In some cases, the health care professional may believe that informing the parents or caregiver before the police or another care service is available creates a greater risk of injury to the child and / or themselves; in such circumstances, you can choose to delay the information to the parent or guardian. Representatives of child care services and social workers can however help the doctor determine the likelihood of subsequent harm and thus identify the best choice for the child. The best options include hospitalization for protective purposes, placement with relatives or in temporary housing (sometimes an entire family is moved out of the home of a violent partner), temporary custody of guardianship centers, or people who have given availability or a return home with timely medical and social follow-up. Close monitoring of the family environment and the needs of carers is essential, after contact with various public services [37-42].

In all these hypotheses, the Psychology Service is always provided to support the professionals and the actors of the events narrated, to guarantee a personalized path that assists, supports or intervenes with targeted therapy for those who need it most, also providing the hypothesis of the involvement of the Psychiatric Service if the psychopathological seriousness is such as to presuppose the need for an integrative drug therapy, as in the hypothesis of personality disorders and psychopathy. Beyond the need to neutralize any dangers deriving from the behavior of the parents or the caregiver, child maltreatment (especially in victims who are already aged from the second childhood onwards) can produce consequences of various entities in the short and long term. Research has confirmed a significant relationship between child abuse and depression, anxiety disorders, eating disorders, sexual dysfunctions, dissociative disorders, personality disorders, post-traumatic disorders, and drug abuse [43-63] to be treated with psychotherapy [64] and possible pharmacological contribution.

\section{Conclusions}

Prevention of abuse must be included in every visit to the health care services of minors through the education of parents and the identification of risk factors. Families at risk must be referred to appropriate social services. In particular, parents who have been victims of mistreatment in childhood, having a greater risk of becoming abusers of their child, even indirectly, need more widespread support, institutionalized by law. If the infant is neonatal or in any case in early childhood and the injuries are multiple and serious then it is logical to think that the attention should be immediately shifted to the mental health of the parents and / or the caregiver, as they could probably suffer from a clinically relevant psychopathological condition, up to the most severe forms such as personality disorders and psychopathy.

\section{References}

1. Perrotta G (2019) Psicologia clinica, Luxco Ed.

2. Ali F, Chamorro-Premuzic T (2010) The dark side of love and life satisfaction: Associations with intimate relationships, psychopathy and Machiavellianism. Personality and Individual Differences 48: 228-233. Link: https://bit.ly/2GwpeFr

3. Anderson NE, Steele VR, Maurer JM, Rao V, Koenigs MR, et al. (2017) Differentiating emotional processing and attention in psychopathy with functional neuroimaging. Cogn Affect Behav Neurosci 17: 491-515. Link: https://bit.ly/2GmK1LQ

4. Blair RJR (1999) Responsiveness to distress cues in the child with psychopathic tendencies. Personality and Individual Differences 27: 135-145. Link: https://bit.ly/34nl1Mk

5. Adams HM, Luevano VX, Jonason PK (2014) Risky business: Willingness to be caught in an extra-pair relationship, relationship experience, and the Dark Triad. Personality and Individual Differences 66: 204-207. Link: https://bit.ly/2SyBNIW

6. Brumbach BH, Figueredo AJ, Ellis BJ (2009) Effects of harsh and unpredictable environments in adolescence on development of life history strategies: A longitudinal test of an evolutionary model. Human Nature 20: 25-51. Link: https://bit.ly/3jzs3nB

7. Cassidy J (1994) Emotion regulation: Influences of attachment relationships In N. Fox (Ed.), The development of emotion regulation. Monogr Soc Res Child Dev 59: 228-249. Link: https://bit.ly/34pG8ha

8. Conradi HJ, Boertien SD, Cavus H, Verschuere B (2016) Examining psychopathy from an attachment perspective: The role of fear of rejection and abandonment. Journal of Forensic Psychiatry \& Psychology 27: 92-109. Link: https://bit.ly/34qVORg

9. Craig RL, Gray NS, Snowden RJ (2013) Recalled parental bonding, current attachment, and the triarchic conceptualisation of psychopathy. Personality and Individual Differences 55: 345-350. Link: https://bit.ly/3d9H79a

10. Jenny C,Crawford-Jakubiak JE (2013) Committee on Child Abuse and Neglect; American Academy of Pediatrics: The evaluation of children in the primary care setting when sexual abuse is suspected. Pediatrics 132 : e558-e567. Link: https://bit.ly/2HUVAKI

11. Fanti KA, Kyranides MN, Georgiou G, Petridou M, Colins OF, et al. (2012) Callous-unemotional, impulsive-irresponsible, and grandiose-manipulative traits: Distinct associations with heart rate, skin conductance, and startle responses to violent and erotic scenes. Psychophysiology 54: 663-672. Link: https://bit.ly/2Sucf9F 
12. Fanti KA, Panayiotou G, Lazarou C, Michael R, Georgiou G (2016) The better of two evils? Evidence that children exhibiting continuous conduct problems high or low on callous- unemotional traits score on opposite directions on physiological and behavioral measures of fear. Dev Psychopathol 28: 185198. Link: https://bit.ly/34qW5ng

13. Hare RD (1991) The Hare Psychopathy Checklist-Revised. Toronto, ON Canada: Multi-Health Systems.

14. Hare RD (1996) Psychopathy: A clinical construct whose time has come. Criminal Justice and Behavior 23: 25-54. Link: https://bit.ly/3liaVDm

15. Hare RD (2003) Manual for the Hare Psychopathy Checklist-Revised,. Toronto, ON, Canada: Multi-Health Systems

16. Flexon JL (2016) Callous-unemotional traits and differently motivated aggression: An examination of variants in a noninstitutionalized sample. Youth Violence and Juvenile Justice 14: 367-389. Link: https://bit.ly/3nfzO4p

17. Hawes DJ, Dadds MR, Frost ADJ, Hasking PA (2011) Do childhood callousunemotional traits drive change in parenting practices? J Clin Child Adolesc Psychol 40: 507-518. Link: https://bit.ly/2Gwq9Wp

18. Herrera PM (1997) La familia funcional y disfuncional, un indicador de salud Rev Cubana Med Gen Integr 13. Link: https://bit.ly/3jLNIsA

19. Hicks BM, Markon KE, Patrick CJ, Krueger RF, Newman JP (2004) Identifying psychopathy subtypes on the basis of personality structure. Psychol Assess 16: 276-288. Link: https://bit.ly/34vB4Yi

20. Jakobwitz S, Egan V (2006) The dark triad and normal personality traits. Personality and Individual Differences 40: 331-339. Link: https://bit.ly/33ylhZL

21. Jonason PK, Kavanagh P (2010) The dark side of love: Love styles and the dark triad. Personality and Individual Differences 49: 606-610. Link: https://bit.ly/2F2ZuQj

22. Jonason PK, Luevano VX, Adams HM (2012) How the dark triad traits predict relationship choices. Personality and Individual Differences 53: 180-184. Link: https://bit.ly/3d4iURj

23. Jonason PK, Valentine KA, Li NP, Harbeson CL (2011) Mate-selection and the dark triad: Facilitating a short-term mating strategy and creating a volatile environment. Personality and Individual Differences 51: 759-763. Link: https://bit.ly/30CLFzJ

24. Jonason PK, Webster GD (2012) A protean approach to social influence: Dark triad personalities and social influence tactics. Personality and Individual Differences 52: 521-526. Link: https://bit.ly/2GGKibY

25. Kahn RE, Frick PJ, Youngstrom EA, Kogos Youngstrom J, Feeny NC, Findling RL (2013) Distinguishing primary and secondary variants of callous-unemotiona traits among adolescents in a clinic-referred sample. Psychol Assess 25 966-978. Link: https://bit.ly/3leWIHd

26. Kimonis ER, Fanti KA, Goulter N, Hall J (2016) Affective startle potentiation differentiates primary and secondary variants of juvenile psychopathy. Dev Psychopathol 24: 1091-1103. Link: https://bit.ly/2SsbzBR

27. Kimonis ER, Fanti KA, Isoma Z, Donoghue K (2013) Maltreatment profiles among incarcerated boys with callous-unemotional traits. Child Maltreat 18 : 108-121. Link: https://bit.ly/30B7SOC

28. Kimonis ER, Frick PJ, Cauffman E, Goldweber A, Skeem J (2012) Primary and secondary variants of juvenile psychopathy differ in emotional processing Dev Psychopathol 24: 1091-1103. Link: https://bit.ly/3d6hOof

29. Kimonis ER, Goulter N, Hawes DJ, Wilbur RR, Groer MW (2017) Neuroendocrine factors distinguish juvenile psychopathy variants. Dev Psychobiol 59: 161173. Link: https://bit.ly/3iBnNCJ

30. Kochanska G (1995) Children's temperament, mother's discipline, and security of attachment: Multiple pathways to emerging internalization. Child Development 66: 597-615. Link: https://bit.ly/3jBzkmH

31. Kochanska G (1997) Multiple pathways to conscience for children with different temperaments: From toddlerhood to age 5. Dev Psychol 33: 228-240. Link: https://bit.ly/3iGaHUY

32. Kochanska G, Boldt LJ, Kim S, Yoon JE, Philibert RA (2015) Developmenta interplay between children's biobehavioral risk and the parenting environment from toddler to early school age: Prediction of socialization outcomes in preadolescence. Dev Psychopathol 27: 775-790. Link: https://bit.ly/2HX1s5T

33. Kyranides MN, Fanti KA, Sikki M, Patrick CJ (2016) Triarchic dimensions of psychopathy in young adulthood: Associations with clinical and physiological measures after accounting for adolescent psychopathic traits. Personality Disorders: Theory, Research, and Treatment 8: 140-149. Link: https://fla.st/2GFOt8d

34. Levenson M, Kiehl K, Fitzpatrick C (1995) Assessing psychopathic attributes in a non-institutionalized population. Journal of Personality and Social Psychology 68: 151-158. Link: https://bit.ly/3ln0gaB

35. Mack TD, Hackney AA, Pyle M (2011) The relationship between psychopathic traits and attachment behavior in a non-clinical population. Personality and Individual Differences 51: 584-588. Link: https://bit.ly/3jztxyb

36. Pierce MC, Kaczor K, Aldridge S, O’Flynn J, Lorenz DJ (2010) Bruising characteristics discriminating physical child abuse from accidental trauma. Pediatria 125: 67-74. Link: https://bit.ly/36C67Vc

37. Savard C, Brassard A, Lussier Y, Sabourin S (2015) Subclinical psychopathic traits and romantic attachment in community couples: A dyadic approach. Personality and Individual Differences 72: 128-134. Link: https://bit.ly/3cZzoue

38. Savard C, Sabourin S, Lussier Y (2006) Male sub-threshold psychopathic traits and couple distress. Personality and Individual Differences 40: 931-942. Link: https://bit.ly/34te0cP

39. Schimmenti A, Passanisi A, Pace U, Manzella S, Di Carlo G, et al. (2014) The relationship between attachment and psychopathy: A study with a sample of violent offenders. Current Psychology: A Journal for Diverse Perspectives on Diverse Psychological 33: 256-270. Link: https://bit.ly/2F2mn6q

40. Unrau AM, Morry MM (2017) The subclinical psychopath in love: Mediating effects of attachment styles. Journal of Social and Personal Relationships. 1-29. Link: https://bit.ly/33v25vU

41. Viding E, Blair RJ, Moffitt TE, Plomin R (2005) Evidence for substantial genetic risk for psychopathy in 7-year-olds. J Child Psychol Psychiatry 46: 592-597. Link: https://bit.ly/2SscvGn

42. Yildirim BO, Derksen JJL (2015) Clarifying the heterogeneity in psychopathic samples: Towards a new continuum of primary and secondary psychopathy Aggression and Violent Behavior 24: 9-41. Link: https://bit.ly/2F89sjA

43. Maguire SA, Watts PO, Shaw AD, Holden S, Taylor RH, et al. (2013) Retinal haemorrhages and related findings in abusive and non-abusive head trauma: A systematic review. Eye (Lond) 27: 28-36. Link: https://bit.ly/3jCZ8iC

44. Perrotta G (2019) Anxiety disorders: definitions, contexts, neural correlates and strategic therapy. J Neur Neurosci 6: 046. Link: https://bit.ly/34vMiMH

45. Perrotta G (2019) Neural correlates in eating disorders: Definition, contexts and clinical strategies. J Pub Health Catalog 2: 137-148. Link: https://bit.ly/36z79R

46. Perrotta G (2019) Post-traumatic stress disorder: Definition, contexts, neura correlations and cognitive-behavioral therapy. J Pub Health Catalog 2: 40-47. Link: https://bit.ly/3nhV60K

47. Perrotta G (2019) Sleep-wake disorders: Definition, contexts and neura correlations. J Neurol Psychol 7: 09. 
48. Perrotta G (2019) Depressive disorders: Definitions, contexts, differential diagnosis, neural correlates and clinical strategies. Archives of Depression and Anxiety 5: 009-033. Link: https://bit.ly/34plywg

49. Perrotta G (2019) Panic disorder: definitions, contexts, neural correlates and clinical strategies. Current Trends in Clinical \& Medical Sciences. Curr Tr Clin Med Sci 1: 2019. Link: https://bit.ly/30D997U

50. Perrotta G (2019) Obsessive-Compulsive Disorder: definition, contexts, neural correlates and clinical strategies. 1: 08-16. Link: https://bit.ly/2I1u4Lt

51. Perrotta G (2019) Behavioral addiction disorder: definition, classifications, clinical contexts, neural correlates and clinical strategies. J Addi Adol Beh 2 : 10. Link: https://bit.ly/2GH59Mk

52. Perrotta G (2019) Delusions, paranoia and hallucinations: definitions, differences, clinical contexts and therapeutic approaches. Cientific Journal of Neurology (CJNE) 1: 22-28.

53. Perrotta G (2019) Paraphilic disorder: definition, contexts and clinical strategies. 1: 4. Link: https://bit.ly/3cZX9IV

54. Perrotta G (2019) Attention Deficit Hyperactivity Disorder: definition, contexts, neural correlates and clinical strategies. J Addi Adol Beh 2. Link: https://bit.ly/34rydQm

55. Perrotta G (2019) Specific learning and language disorders: definitions, differences, clinical contexts and therapeutic approaches. J Addi Adol Beh 2 . Link: https://bit.ly/2F4U4o7

56. Perrotta G (2019) Tic disorder: definition, clinical contexts, differential diagnosis, neural correlates and therapeutic approaches. J Neurosci Rehab 2019: 1-6. Link: https://bit.ly/2GKal1Z

57. Perrotta G (2019) Bipolar disorder: definition, differential diagnosis, clinical contexts and therapeutic approaches. J Neuroscience Neurological Surgery 5.
58. Perrotta G (2019) The reality plan and the subjective construction of one's perception: the strategic theoretical model among sensations, perceptions, defence mechanisms, needs, personal constructs, beliefs system, social influences and systematic errors. Journal of Clinical Research and Reports. J Clinical Research and Reports 1 .

59. Perrotta G (2020) Psychological trauma: definition, clinical contexts, neura correlations and therapeutic approaches. Current Research in Psychiatry and Brain Disorders. Curr Res Psychiatry Brain Disord: CRPBD-100006. Link: https://bit.ly/2StG7mP

60. Perrotta G (2020) Human mechanisms of psychological defence: definition, historical and psychodynamic contexts, classifications and clinical profiles. International Journal of Neurorehabilitation. Int J Neurorehabilitation Eng 7. Link: https://bit.ly/3jCZS7o

61. Perrotta G (2020) Suicidal risk: definition, contexts, differential diagnosis, neural correlates and clinical strategies. J Neuroscience and Neurological Surgery $6: 114$

62. Perrotta G (2020) Pathological gambling in adolescents and adults: definition clinical contexts, differential diagnosis, neural correlates and therapeutic approaches. ES J Neurol 1: 1004. Link: https://bit.ly/34qqjqh

63. Perrotta G (2020) The concept of altered perception in "body dysmorphic disorder": the subtle border between the abuse of selfies in social networks and cosmetic surgery, between socially accepted dysfunctionality and the pathological condition. J Neurol Neurol Sci Disord 6: 001-007. Link: https://bit.ly/2Sx20Sc

64. Perrotta G (2020) The strategic clinical model in psychotherapy: theoretical and practical profiles. Review article, Author. Journal of Addiction and Adolescent Behaviour. 3. Link: https://bit.ly/3ddX26t

\section{Discover a bigger Impact and Visibility of your article publication with}

\section{Peertechz Publications}

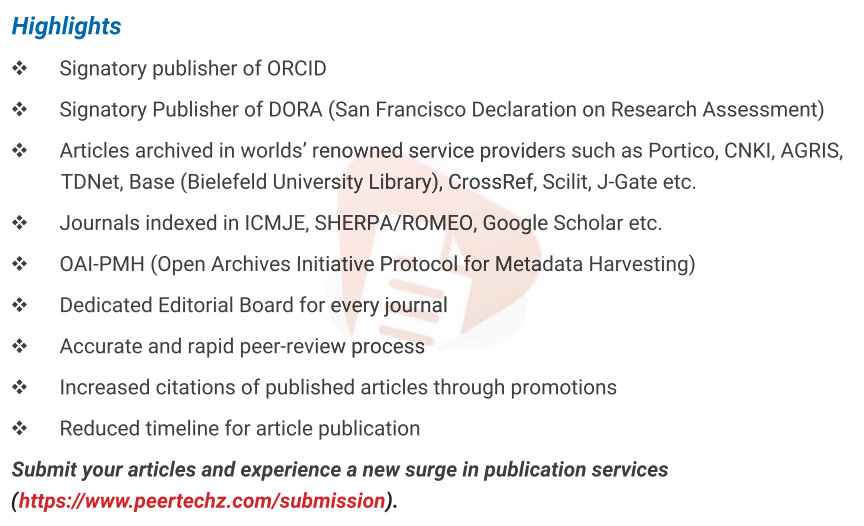

Peertechz journals wishes everlasting success in your every endeavours.

Copyright: ๑ 2020 Perrotta G. This is an open-access article distributed under the terms of the Creative Commons Attribution License, which permits unrestricted use, distribution, and reproduction in any medium, provided the original author and source are credited. 